\title{
Development of Nanostructures in Thermoelectric Pb-Te-Sb Alloys
}

\author{
T. Ikeda ${ }^{1}$, V. Ravi ${ }^{2}$, L. A. Collins ${ }^{2}$, S. M. Haile ${ }^{1}$ and G. J. Snyder ${ }^{1}$ \\ ${ }^{1}$ California Institute of Technology; 1200 E. California Boulevard; Pasadena, CA 91125, USA \\ ${ }^{2}$ California State Polytechnic University; 3801 W. Temple Avenue; Pomona, CA 91768, USA
}

\begin{abstract}
In analogy to recent demonstrations of enhanced thermoelectric properties in superlattice materials, composite structures with nanoscale features promise dramatic improvements in the figure of merit of thermoelectric materials. Fabrication of nanostructured thermoelectric materials via bulk synthesis is an attractive route for commercial applications. Nanometer scale lamellae of $\mathrm{PbTe}$ and $\mathrm{Sb}_{2} \mathrm{Te}_{3}$ form when quenched eutectic $\mathrm{PbTe}-\mathrm{Sb}_{2} \mathrm{Te}_{3}$ melt is subsequently annealed. The lamellar spacing depends on the temperature and time of the anneal. The mechanism for the development of the nanostructures can be characterized by examining the fraction of material transformed as a function of anneal time. Preliminary analysis of the shape factor exponent reveals that the evolution of the nanostructured lamellae is likened to the thickening of very large plates. The coarsening of the lamellar spacing is also examined as a function of time.
\end{abstract}

\section{Keywords}

Thermoelectric, Lamellar spacing, Fraction transformed, Coarsening

\section{Introduction}

The development of efficient thermoelectric devices for both space and terrestrial applications requires the discovery of materials with a high thermoelectric figure of merit, $z T$, defined as $S^{2} \sigma \mathrm{T} / \kappa$, where $S$ is the Seebeck coefficient, $\sigma$ the electrical conductivity and $\kappa$ the thermal conductivity. Materials investigated and optimized over the past 50 years have been conventional, simple semiconductors. Examples include bismuth telluride alloys, lead telluride alloys and silicon germanium alloys [1]. Here we examine a system of two immiscible thermoelectric materials: $\mathrm{PbTe}_{-} \mathrm{Sb}_{2} \mathrm{Te}_{3}$. This ternary system was selected for investigation because it has been shown that the metastable compound $\mathrm{Pb}_{2} \mathrm{Sb}_{6} \mathrm{Te}_{11}$ appears at a composition close to that of the eutectic $[2,3]$ and decomposes into two thermoelectric compounds, $\mathrm{PbTe}$ and $\mathrm{Sb}_{2} \mathrm{Te}_{3}$, forming nano-sized lamellar structures [4]. Ideally, such structures can result in improved $z T$ [5-7], presumably by enhanced phonon scattering [8], which decreases $\kappa$. In the present work, eutectic $\mathrm{PbTe}-\mathrm{Sb}_{2} \mathrm{Te}_{3}$ alloys were synthesized by quenching in water from the liquid state and then annealed at several temperatures to examine the time evolution of fraction transformed and inter-lamellar spacing. Mapping and understanding the microstructure evolution pathway is an essential first step for ultimately utilizing such an approach for tuning properties.

\section{Experimental procedure}

Samples with overall composition matching the $\mathrm{Pb}_{2} \mathrm{Sb}_{6} \mathrm{Te}_{11}$ compound were prepared by rapid cooling of the melt. Stoichiometric quantities of $\mathrm{Pb}, \mathrm{Sb}$, and $\mathrm{Te}$ granules (99.999\%, Alfa Aesar) were loaded into $12 \mathrm{~mm}$ quartz ampoules and then sealed under a vacuum of approximately 4 $\times 10^{-3} \mathrm{~Pa}$ to prevent oxidation at high temperatures. Samples were then melted in vertical furnace for one day at $1023 \mathrm{~K}$. Alloys were subsequently water quenched and then annealed in the $533 \mathrm{~K}$ to $773 \mathrm{~K}$ range. The resulting ingots were cut, mounted in epoxy pucks and polished finally with $0.3 \mu \mathrm{m}$ $\mathrm{Al}_{2} \mathrm{O}_{3}$ paste. The microstructures were observed using a field emission-scanning electron microscope (Carl Zeiss LEO 1550 VP) equipped with a Robinson backscattered electron (BSE) detector for its high compositional contrast capabilities. The accelerating voltage was $20 \mathrm{kV}$. The microstructures were digitally analyzed using an image analysis program (Macscope, Mitani Corp.) to determine the inter-lamellar spacing (ILS) and the fraction transformed $(Y)$. The chemical compositions of the constituent phases in each alloy were measured using a wavelength dispersive X-ray spectrometer (WDS, JXA-8200, JEOL Ltd.). For the WDS measurements, $\mathrm{Sb}, \mathrm{Te}$ and $\mathrm{PbS}$ samples were used as standards for ZAF conversion [9] from intensities of $\mathrm{Pb} \mathrm{M}_{\alpha}, \mathrm{Sb} \mathrm{L}_{\alpha}$ and $\mathrm{Te} \mathrm{L}_{\alpha}$ to
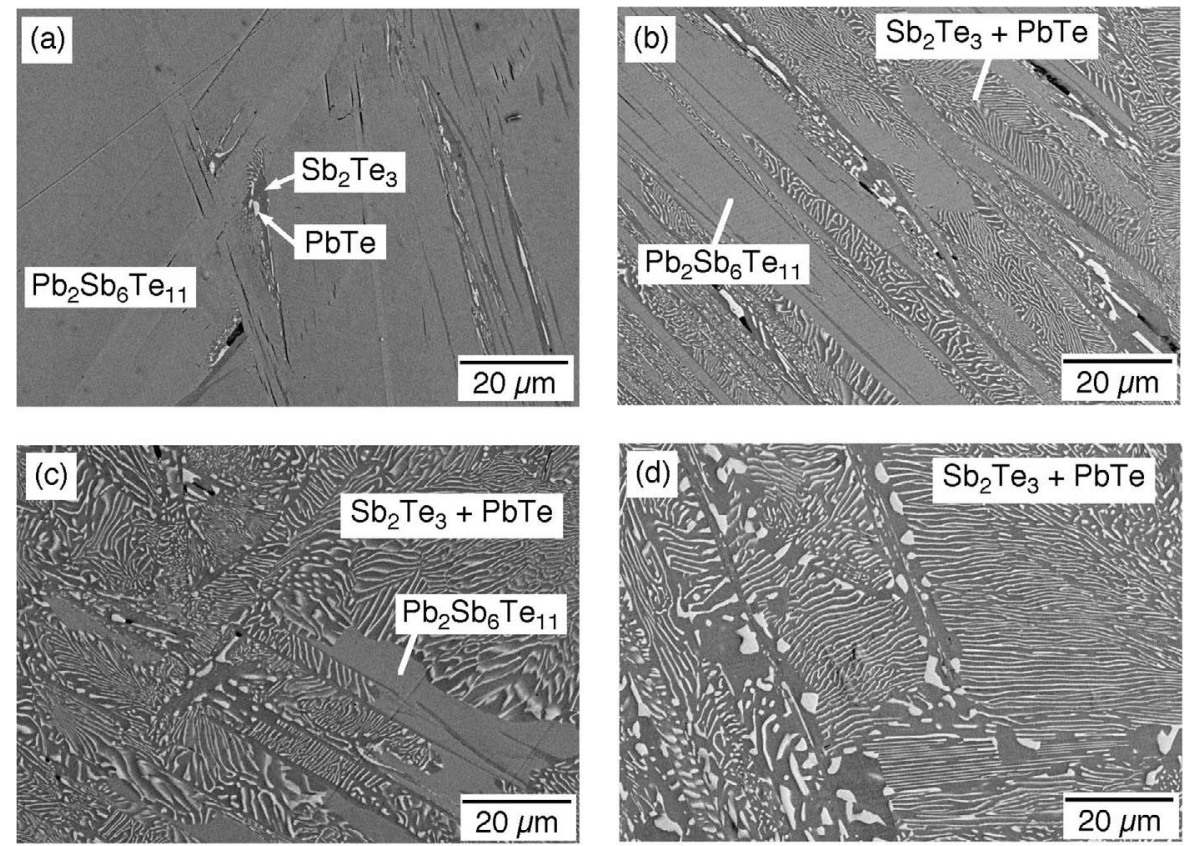

Figure 1: Microstructure of $\mathrm{Pb}_{10.5} \mathrm{Sb}_{31.6} \mathrm{Te}_{57.9}$ : (a) as quenched, and annealed at 773 $\mathrm{K}$ for (b) $900 \mathrm{~s}$, (c) $3600 \mathrm{~s}$ and (d) $4.32 \times 10^{5} \mathrm{~s}$ (5 days). Bright, dark gray and gray phases are $\mathrm{PbTe}, \mathrm{Sb}_{2} \mathrm{Te}_{3}$ and $\mathrm{Pb}_{2} \mathrm{Sb}_{6} \mathrm{Te}_{11}$, respectively. 
concentrations. X-ray diffraction (XRD) experiments (Phillips X-Pert Pro diffractometer, $\mathrm{Cu} \mathrm{K}-\alpha$ radiation, $15^{\circ} \leq 2 \theta \leq 45^{\circ}$ ) were performed directly on the as-prepared ingots to identify phases.

\section{Results and Discussion}

\section{Microstructure}

Examples of the range of microstructures obtained using the different heat treatments described is shown in Figure 1. Figure 1 (a) shows the microstructure of the asquenched alloy (before annealing). The long dark features are $\mathrm{Sb}_{2} \mathrm{Te}_{3}$, within which are embedded bright islands of $\mathrm{PbTe}$. The majority gray phase is metastable $\mathrm{Pb}_{2} \mathrm{Sb}_{6} \mathrm{Te}_{11}$ [4]. The remaining images in Figure 1 show the microstructure after annealing at $773 \mathrm{~K}$ for (b) $15 \mathrm{~min}$, (c) $1 \mathrm{hr}$ and (d) 5 days. The fine lamellar structure in Fig. 1 (b), consisting of $\mathrm{Sb}_{2} \mathrm{Te}_{3}$ (dark) and PbTe (bright) phases, is attributed to the decomposition of $\mathrm{Pb}_{2} \mathrm{Sb}_{6} \mathrm{Te}_{11}$ compound, whereas the uniform gray regions remain undecomposed. Further annealing results in the coarsening of the lamellar structure and additional transformation of undecomposed regions as evident in Figs 1 (c) and (d). The chemical compositions of $\mathrm{PbTe}$ and $\mathrm{Sb}_{2} \mathrm{Te}_{3}$ phases were measured by WDS on the few, relatively large $(>1 \mu \mathrm{m})$ transformed regions (not lamellae) that are formed during the quenching step [4]. It is clear from the data (Table I) that the solubilities of $\mathrm{Sb}$ in $\mathrm{PbTe}$ and $\mathrm{Pb}$ in $\mathrm{Sb}_{2} \mathrm{Te}_{3}$ are quite limited.

\begin{tabular}{|c|c|c|c|c|}
\hline \multicolumn{5}{|c|}{$\begin{array}{l}\text { Table I. Composition of PbTe and } \mathrm{Sb}_{2} \mathrm{Te}_{3} \text { phases at } 573 \text {, } \\
673 \text { and } 773 \mathrm{~K} \text { ( } 5 \text { day anneal) measured by WDS. }\end{array}$} \\
\hline Temp. & Phase & $\mathrm{Pb} /$ at. $\%$ & $\mathrm{Sb} /$ at.\% & $\mathrm{Te} /$ at. $\%$ \\
\hline \multirow[t]{2}{*}{$773 \mathrm{~K}$} & $\mathrm{PbTe}$ & $46.1 \pm 0.5$ & $3.08 \pm 0.35$ & $50.8 \pm 0.2$ \\
\hline & $\mathrm{Sb}_{2} \mathrm{Te}_{3}$ & $1.19 \pm 0.08$ & $39.4 \pm 0.2$ & $59.4 \pm 0.1$ \\
\hline \multirow[t]{2}{*}{$673 \mathrm{~K}$} & $\mathrm{PbTe}$ & $43.0 \pm 3.9$ & $5.6 \pm 3.2$ & $51.3 \pm 0.7$ \\
\hline & $\mathrm{Sb}_{2} \mathrm{Te}_{3}$ & $3.15 \pm 0.48$ & $37.6 \pm 0.4$ & $59.3 \pm 0.2$ \\
\hline \multirow[t]{2}{*}{$573 \mathrm{~K}$} & $\mathrm{PbTe}$ & $43.8 \pm 0.8$ & $4.5 \pm 0.6$ & $51.7 \pm 0.7$ \\
\hline & $\mathrm{Sb}_{2} \mathrm{Te}_{3}$ & $3.6 \pm 0.9$ & $36.3 \pm 1.1$ & $60.1 \pm 0.6$ \\
\hline
\end{tabular}

\section{Fraction transformed}

Figure 2 shows the variation of volume fraction transformed as a function of annealing time, as determined from the microstructural analysis. The fraction transformed increases with increasing time for all annealing temperatures (573, 673 and $773 \mathrm{~K}$ ), and reaching a given transformation fraction requires a significantly longer anneal time at $573 \mathrm{~K}$ than it does at higher temperature. Furthermore, the two high temperature anneals at 673 and $773 \mathrm{~K}$ appear to track quite closely, transforming almost completely after 5 days of annealing. The XRD patterns obtained from the as-quenched sample and from those annealed at $773 \mathrm{~K}$ are compared in Figure 3. Peak assignments for $\mathrm{PbTe}$ and $\mathrm{Sb}_{2} \mathrm{Te}_{3}$ were made with the use of the JCPDS data base. The major peaks of the quenched sample, which is primarily $\mathrm{Pb}_{2} \mathrm{Sb}_{6} \mathrm{Te}_{11}$ phase, can be identified with the $\mathrm{PbSb}_{2} \mathrm{Te}_{4}$ structure reported by Shelimova et al. [10] $(\mathrm{R} \overline{3} \mathrm{~m}, \mathrm{a}=0.4350 \mathrm{~nm}$ and $\mathrm{c}=4.1712$ $\mathrm{nm})$. As the annealing time increases, the $\mathrm{Pb}_{2} \mathrm{Sb}_{6} \mathrm{Te}_{11}$ peaks diminish in intensity and then disappear, consistent with the conclusion from the microstructural observations that the $\mathrm{Pb}_{2} \mathrm{Sb}_{6} \mathrm{Te}_{11}$ phase decomposes into $\mathrm{PbTe}$ and $\mathrm{Sb}_{2} \mathrm{Te}_{3}$. Diffraction peaks due to the $\mathrm{Pb}_{2} \mathrm{Sb}_{6} \mathrm{Te}_{11}$ phase still exist after annealing at $773 \mathrm{~K}$ for $15 \mathrm{~min}$, and are absent after annealing for 5 days indicating the completion of the transformation. This is again consistent with the microstructural observations.
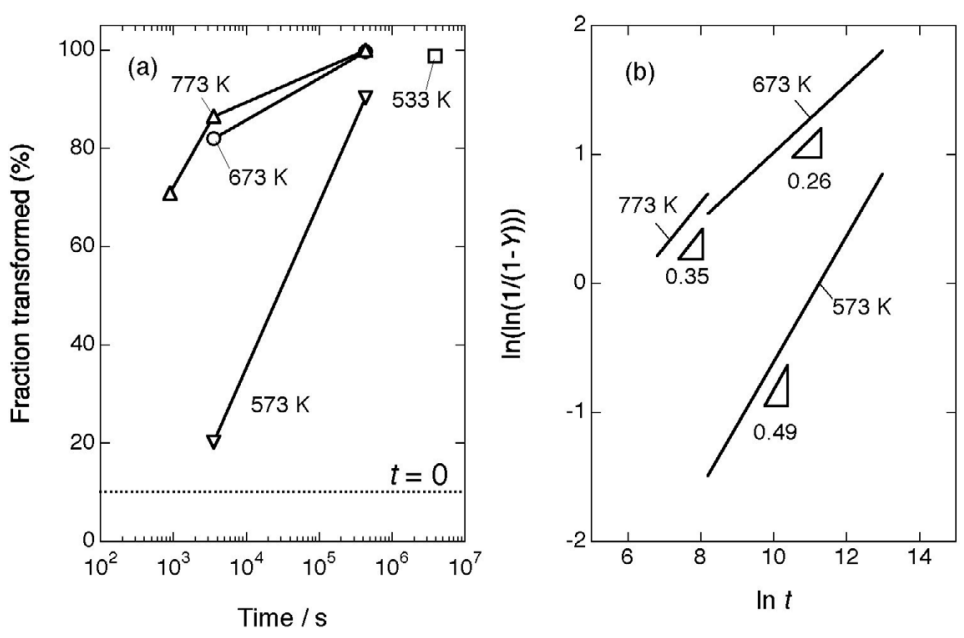

Figure 2: (a) Variation of fraction transformed with annealing time. (b) Plots of $\ln (\ln 1 /(1-Y))$ vs. $\ln t$. The number shown for each temperature in the figure indicates the exponent $n$.

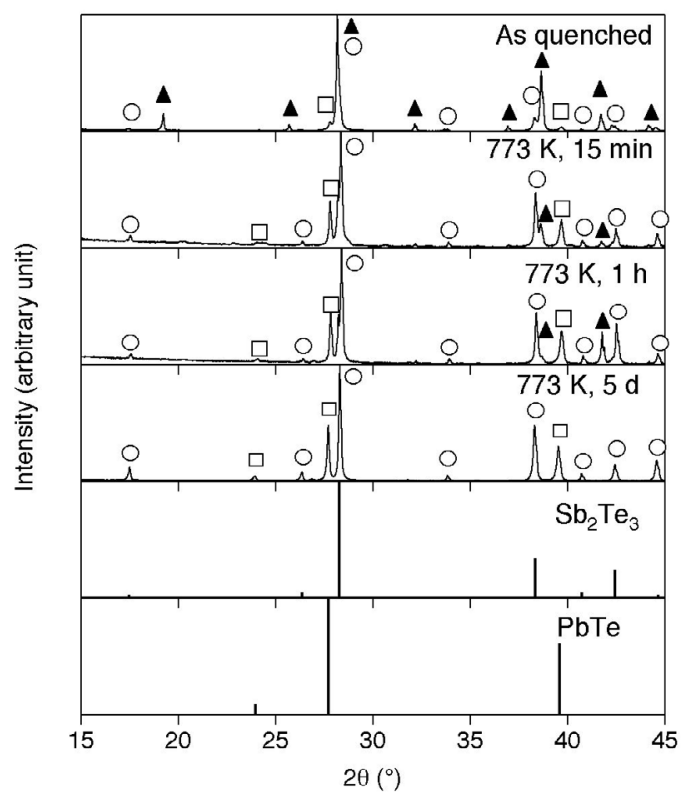

Figure 3: $\mathrm{XRD}$ profiles obtained from $\mathrm{Pb}_{10.5} \mathrm{Sb}_{31.6} \mathrm{Te}_{57.9}$ nonannealed and annealed at $773 \mathrm{~K}$ for $900 \mathrm{~s}, 3600 \mathrm{~s}$ and 4.32 $\times 10^{5} \mathrm{~s}$ (5 days). Open squares $(\square)$, open circles $(O)$ and solid triangles $(\boldsymbol{\Delta})$ show the peaks from $\mathrm{PbTe}, \mathrm{Sb}_{2} \mathrm{Te}_{3}$ and $\mathrm{Pb}_{2} \mathrm{Sb}_{6} \mathrm{Te}_{11}$ phases, respectively.

The time $t$ dependence of the volume fraction transformed $Y$ for a nucleation and growth dominated mechanism is described by the Kolmogorov-Johnson-Mehl-Avrami (KJMA) equation [11-15],

$$
Y(t)=1-\exp \left(-K t^{n}\right)
$$


where $K$ is a temperature dependent parameter, which is constant for isothermal growth conditions, and $n$ is the "shape factor," which depends on the growth dimension and is usually between 1 and 4 . This equation can be transformed to

$$
\ln \left(\ln \left(\frac{1}{1-Y}\right)\right)=\ln K+n \ln t,
$$

Therefore, a plot of $\ln (\ln (1 /(1-Y)))$ versus $\ln t$ (Figure 2 (b)) should result in a straight line. In the plot, the slope of the line is the exponent $n$, which depends on experimental conditions. The shape factor $n$ for the present study ranges from 0.26 to 0.49 (although the $n=0.26$ value for $673 \mathrm{~K}$ is less reliable due to the nearly $100 \%$ transformation percentage after 15 days). Machlin [16] points out that different values of $n$ can have different implications depending upon control of the transformation process either by nucleation or by diffusion-controlled growth. In the case of eutectoid reactions or interface controlled reactions, the values of $n$ range from 1 to 4 , whereas the value of $n$ range from 0.5 to 2.5 for diffusion controlled processes. The values of $n$ in this study appear to indicate that "thickening of very large plates" [16] is the growth mechanism. However, it should be noted that the plots in Fig. 2 (b) are generated on the basis of extremely limited data and these values of $n$ and the attendant interpretation are tentative at best. From the microstructural features of Figure 1 (b), it appears that the transformation starts from the interface between $\mathrm{Pb}_{2} \mathrm{Sb}_{6} \mathrm{Te}_{11}$ (matrix phase) and $\mathrm{Sb}_{2} \mathrm{Te}_{3}$ (thin dark phase). Fig. 1 (c) and (d) show that new colonies of lamellae are nucleated and that simultaneously existing lamellae become thicker and longer. This observation is consistent with the interpretation proposed above.

\section{Inter-lamellar Spacing}

To determine the distribution of inter-lamellar spacing (ILS), the distances between all neighboring lamellae in at least seven SEM images (one image typically includes 200600 lamellae) were examined. Figure 4 shows the distribution of ILS after annealing at 773 $\mathrm{K}$ for (a) $15 \mathrm{~min}$, (b) $1 \mathrm{~h}$, and (c) and $5 \mathrm{~d}$. All the histograms have broad tails at the larger ILS side of the peaks and narrow ones at the smaller ILS side. In addition, the maxima are located at smaller ILS values for shorter annealing times.

\section{Modeling of Distribution of Inter-lamellar Spacing}

The distribution of ILS is assumed to include the contribution due to the angle of the lamellae to the observation surface as well as the distribution of true spacing. In order to take into using Eq. (3). account the geometric effect of the distribution in observation angles and extract from the apparent ILS distribution parameters relating to the true ILS, an analytical expression for the distribution of ILS has been derived [17]:

$$
F\left(h_{1}, h_{2}\right)=\frac{\int_{h_{1}}^{h_{2}} \frac{1}{h^{4}}\left|\int_{0}^{h} e^{-\frac{\left(d-d_{\text {ave }}{ }^{2}\right.}{2 \sigma^{2}}} \frac{d^{2}}{\sqrt{1-\frac{d^{2}}{h^{2}}}} \mathrm{~d} d\right| \mathrm{d} h}{\int_{0}^{\infty} \frac{1}{h^{4}}\left|\int_{0}^{h} e^{-\frac{\left(d-d_{\text {vac }}\right)^{2}}{2 \sigma^{2}}} \frac{d^{2}}{\sqrt{1-\frac{d^{2}}{h^{2}}}} \mathrm{~d} d\right| \mathrm{d} h},
$$

where $F\left(h_{1}, h_{2}\right)$ is the fraction of lamellae whose apparent ILS are between $h_{1}$ and $h_{2}, d$ is true ILS, $d_{\text {ave }}$ is the weighted average of the true ILS, and $\sigma$ is the standard deviation of the true ILS. The expression in Eq. (3) was fit to the experimental distributions of ILS using least squares methods and the resulting curves are shown in Figure 4. In the fitting procedure, the average and the standard deviation of true ILS are determined as fitting parameters. The values of these parameters are shown in Fig. 4 for the example histograms presented.

\section{Time Evolution of Inter-lamellar Spacing}

Figure 5 shows the variation of ILS with time for three different temperatures. At $773 \mathrm{~K}$, the change in interlamellar spacing with time is initially rapid and subsequently slower. The data for $573 \mathrm{~K}$ and $673 \mathrm{~K}$ are limited, and a linear dependence of the ILS with time cannot be presumed. However, for all temperatures examined, the ILS does increase with increasing annealing time suggesting that coarsening of the lamellar structure occurs. According to Graham and Kraft [18], the variation of ILS is expressed as a linear function of time,
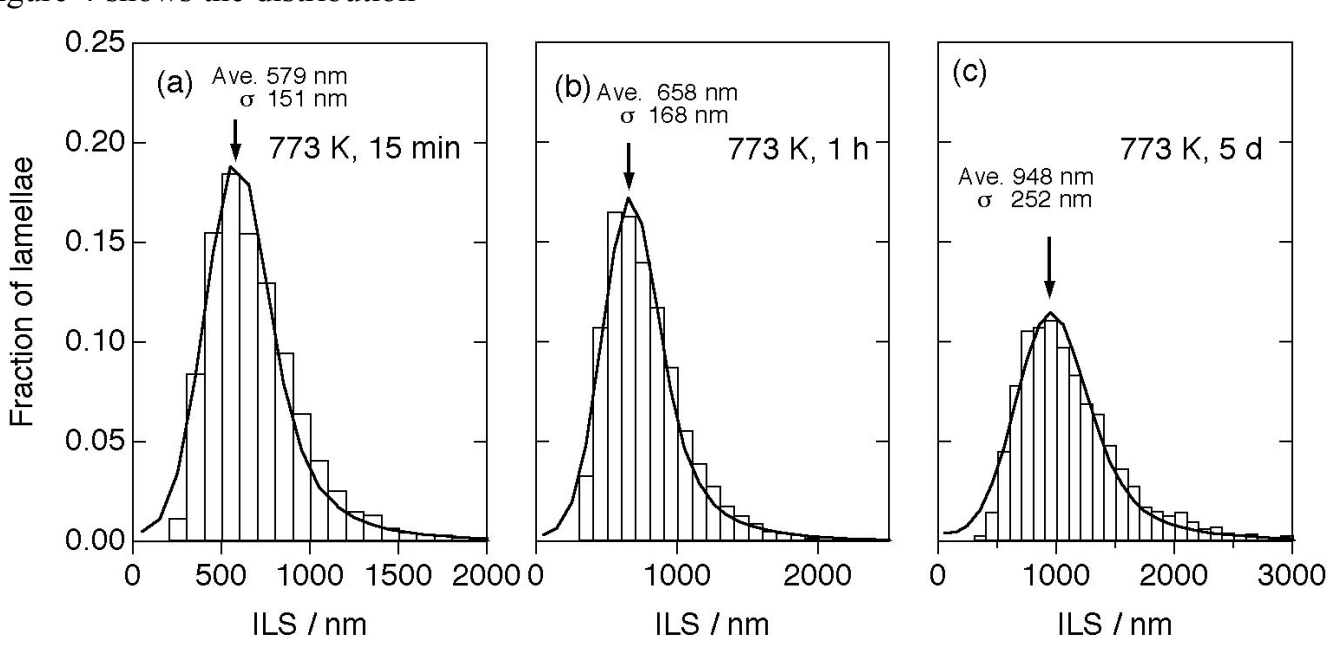

Figure 4: Distribution of inter-lamellar spacing (ILS) in $\mathrm{Pb}_{10.5} \mathrm{Sb}_{31.6} \mathrm{Te}_{57.9}$ alloys annealed at $773 \mathrm{~K}$ for (a) $15 \mathrm{~min}$, (b) $1 \mathrm{~h}$, and (c) 5 days. Solid curves are fit to the experimental histograms 


$$
I L S-I L S_{0}=\frac{K_{1} D t}{T},
$$

where $I L S_{0}$ is the value of $I L S$ at $t=0, K_{1}$ is geometric constant and $D$ is diffusion coefficient. However, in the present case, Eq. (4) has only limited applicability. The increase of ILS with $t$ for $773 \mathrm{~K}$ cannot be modeled with the above equation across the whole region. Accordingly, efforts are continuing on two fronts: (a) obtaining more kinetic data and (b) exploring more complete models, e.g. Cline's [19] analysis of shape and stabilities in eutectic structures, combining the KJMA equation with either Cline's work or the Graham and Kraft approach, etc.

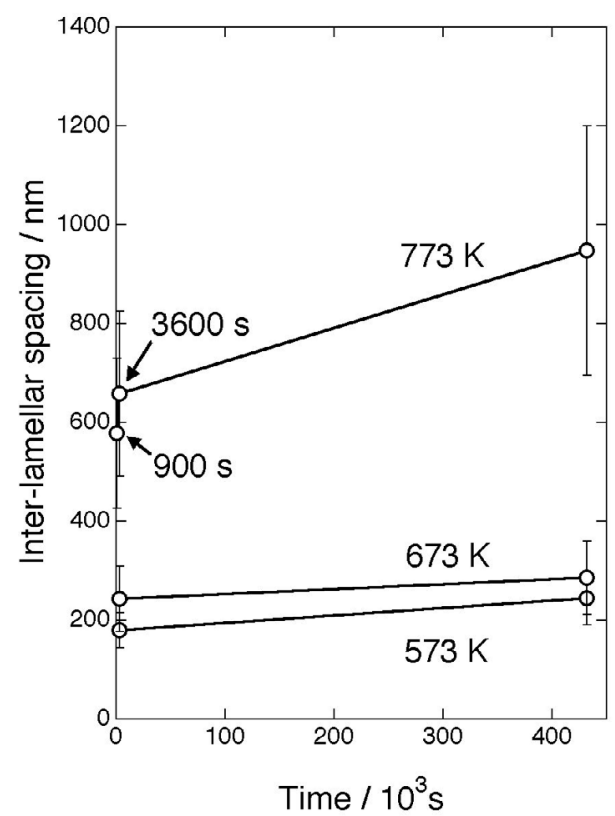

Figure 5: Variation of inter-lamellar spacing with annealing time. Error bars show the standard deviation of true lamellar spacing.

\section{Conclusions}

The metastable compound, $\mathrm{Pb}_{2} \mathrm{Sb}_{6} \mathrm{Te}_{11}$, obtained by water quenching of the melt decomposes into nano-sized lamellae of $\mathrm{PbTe}$ and $\mathrm{Sb}_{2} \mathrm{Te}_{3}$. The lamellae nucleate along the interface between $\mathrm{Pb}_{2} \mathrm{Sb}_{6} \mathrm{Te}_{11}$ (matrix phase) and $\mathrm{Sb}_{2} \mathrm{Te}_{3}$ (thin dark phase). With time new colonies of lamellae are nucleated and existing lamellae get thicker and longer. The values of $n$ (the KJMA exponent) range nominally from 0.3 to 0.5 indicating that "thickening of very large plates" is likely to be the growth mechanism. The inter-lamellar spacing increases with increasing annealing time due to the coarsening of the lamellar structure; however, the Graham and Kraft model does not fit the observed behavior. More data are needed to fit an appropriate model.

\section{Acknowledgments}

This work was supported by the Office of Naval Research. LC was supported by the SURF program at Caltech.

\section{References}

1 D. M. Rowe, CRC Handbook of Thermoelectrics (CRC, Boca Raton, 1995), p. 701.

2 N. K. Abrikosov, E. I. Elagina and M. A. Popova, "The System PbTe-Sb $\mathrm{Te}_{3}$," Inorg. Mater. 1 (1965), 1944-1946.

3 T. Ikeda et al., "Solidification Processing of Alloys in the Pseudo-binary $\mathrm{PbTe}-\mathrm{Sb}_{2} \mathrm{Te}_{3}$ System," Acta Mater (submitted).

4 T. Ikeda et al., "Self-Assembled Nanometer Lamellae of Thermoelectric $\mathrm{PbTe}$ and $\mathrm{Sb}_{2} \mathrm{Te}_{3}$," in preparation.

5 J. C. Caylor et al., "Enhanced Thermoelectric Performance in PbTe-based Superlattice Structures from Reduction of Lattice Thermal Conductivity," Appl. Phys. Lett. 87 (2005), 023105.

6 R. Venkatasubramanian et al., "Thin Film Thermoelectric Devices with High Room-Temperature Figures of Merit," Nature 413 (2001), 597-602.

7 T. C. Harman et al., "Quantum Dot Superlattice Thermoelectric Materials and Devices," Science 297 (2003), 2229-2232.

8 G. Chen, Proc Ninth Intersociety Conference on Thermal and Thermomechanical Phenomena In Electronic Systems 2004 (IEEE Cat. No.04CH37543); p.8.

9 P. E. J. Flewitt and R. K. Wild, Physical Methods for Materials Characterization (Bristol and Philadelphia: Institute of Physics Publishing, 1994), p. 283.

10 L. E. Shelimova et al., "Synthesis and Structure of Layered Compounds in the $\mathrm{PbTe}_{-} \mathrm{Bi}_{2} \mathrm{Te}_{3}$ and $\mathrm{PbTe}-\mathrm{Sb}_{2} \mathrm{Te}_{3}$ Systems," Inorg. Mater. 40, 1264 (2004)

11 A. N. Kolmogorov, "A statistical theory for the recrystallization of metals," Bull. Acad. of Science, USSR, Phys. Ser. 1 (1937), 355-359.

12 W. A. Johnson and R. F. Mehl, "Reaction Kinetics in Processes of Nucleation and Growth," Trans. AIME 135 (1939), 416-458.

13 M. Avrami, "Kinetics of Phase Change. I. General Theory," J. Chem. Phys. 7 (1939), 1103-1112.

14 M. Avrami, "Kinetics of Phase Change. II. Transformation-time Relations for Random Distribution of Nuclei," J. Chem. Phys. 8 (1940), 212-224.

15 M. Avrami, "Granulation, Phase Change and Microstructure. Kinetics of Phase Change. III," J. Chem. Phys. 9 (1941), 177-184.

16 E. S. Machlin, An Introduction to Aspects of Thermodynamics and Kinetics, revised ed. (GIRO Press, Croton-on-Hudson, 1999), p. 249.

17 T. Ikeda et al., unpublished.

18 L. D. Graham and R. W. Kraft, "Coarsening of Eutectic Microstructures at Elevated Temperatures," Trans. Metall. Soc. AIME, 236 (1966), 94-102.

19 H. E. Cline, "Shape Instabilities of Eutectic Composites at Elevated Temperatures," Acta Metall. 19 (1971), 481-490. 